\title{
Inhaltsverzeichnis
}

Vorwort . . . . . . . . . . . . . . . . . 7

A. Einleitung . . . . . . . . . . . . . . . . 9

B. Die Entwicklung der Sprachsituation bis zur Mitte des 19. Jahrhunderts . . . . . . . . 14

I. Grundlagen ． . . . . . . . . . . . 14

a) Die altsächsische Zeit . . . . . . . 14

b) Das Vordringen der höfischen Feudalkultur in Norddeutschland . . . . . 22

II. Die Entstehung und Entwicklung der Siedlungsmundarten . . . . . . 2 s

a) Die westniederdeutschen Mundarten, Allgemeines zur Entstehung der Siedlungsmundarten . . . . . . 26

b) Das Mecklenburgisch-Vorpommersche 30

c) Das Brandenburgische . . . . . . 34

d) Der mittelpommersche Keil und das Land Stargard . . . . . . . . . 37

e) Das Aufgehen des Slawischen in den ostniederdeutschen Mundarten . . . 38

f) Die Ausbildung derostniederdeutschen Mundarten . . . . . . . . . . . 41

III. Die mittelniederdeutsche Schriftsprache der Hansezeit

a) Der Beginn des mittelniederdeutschen Schrifttums . . . . . . .

b) Die Ausbildung der mittelniederdeutschen Schriftsprache . . . 
IV. Der Rückgang des Niederdeutschen vom 16. Jahrhundert bis zur Mitte des 19. Jahrhunderts . . . . . . . . . . . 56

a) Der Untergang der mittelniederdeutschen Schriftsprache . . . .

b) Versuche, die mittelniederdeutsche Schriftsprache zu erneuern . . . . .

c) Die Bildung einer hochdeutschen Umgangssprache in Norddeutschland

d) Das Niederdeutsche lebt in einzelnen Mundarten weiter. Kennzeichen der Mundart. speziell des Mecklenburgischen . . . . . . . . .

e) Die Diskussion um die Existenzberechtigung des Niederdeutschen. .

Die Entwicklung der Sprachsituation seit der Mitte des 19. Jahrhunderts . . . . . . . 92

I. Auf der Grundlage der Volksüberlieferungen wird das Niederdeutsche noch einmal Literatursprache . . . . . . .

a) Die niederdeutsche Volksüberlieferung . . . . . . . . . .

b) Die Dichtung Groths, Reuters und Brinckmans . . . . . . . . . . 95

c) Der Niedergang der Mundartdichtung 106

II. Das Zurückdrängen des Niederdeutschen durch das Zusammenwachsen der deutschen Nation . . . . . . . 107

a) Der wachsende Einfluß der Städte .107

b) Die Wirkung der Gesamtheit der gesellschaftlichen und der ökonomischen Veränderungen . . . . . 116

III. Der letzte Einfluß des Niederdeutschen auf die deutsche Hochsprache . . . . . 123

a) Der Einfluß auf den Wortschatz . . . 123

b) Der Einfluß auf die Aussprache . . . 127 
IV. Die gegenwärtige Sprachsituation .

a) Die Veränderungen innerhalb der Mundart. . . . . . . . . . . 134

b) Die Sprachsituation bei den Erwachsenen . . . . . . . . . . . 140

c) Die Sprachsituation an den Schulen 145

d) Vergleich mit der Sprachsituation in Westdeutschland . . . . . . . . 158

e) Die Situation und die Perspektive der mundartlichen und der mischsprachlichen Dichtung . . . . . . 160

f) Die Pflege des Niederdeutschen . . 168

Textproben . . . . . . . . . . . . . . . 177

Literaturverzeichnis . . . . . . . . . . . 200

\section{Verzeichnis der Karten}

1. Ungefähre Grenze des as. Sprachraumes . . 19

2. Tram/Sprat. . . . . . . . . . . . . . 30

3. Falg'/Brak . . . . . . . . . . . . . . 31

4. Kauken $/$ Koken . . . . . . . . . . . . 33

5. Der Enterich (Westen) . . . . . . . . . 35

6. Der Enterich (Osten) . . . . . . . . . . 36

7. Sod/Pütten . . . . . . . . . . . . . . . . . 39

8. Die niederdeutschen Mundarten . . . . 108

Mit freundlicher Genehmigung der Verfasser wurden die Karten 1 bis 7 folgenden Werken entnommen und, entsprechend der WTB-Reihe, neu gezeichnet:

1. William Foerste, Geschichte der niederdeutschen Mundarten, in: Deutsche Philologie im Aufriß, 1. Bd., 2. Aufl., Berlin und Bielefeld 1957, Sp. 1739.

2., 3., 4., 7. Hermann Teuchert, Entwurf einer mecklenburgischen Sprachgeschichte, in: Wissenschaftliche Zeitschrift der Universität Rostock, gesellschafts- und sprachwiss. Reihe. 7. Jg. (1957/58), S. 197-199.

5., 6. Hermann Teuchert, Die Sprachreste der niederländischen Siedlungen des 12. Jahrhunderts, Neumünster 1944, S. 348-349. 